Artículos

\title{
La dinámica política en la Argentina 2015-2020. Giro, contra giro ¿y después?
}

\author{
The political dynamics in Argentina 2015-2020: Turn, against \\ turn, and then?
}
A dinâmica política na Argentina 2015-2020: Volta, volta, e depois?

\section{Retamozo, Martín; Schuttenberg, Mauricio}

\author{
(iD) Martín Retamozo \\ martin.retamozo@gmail.com \\ Instituto de Investigaciones en Humanidades y \\ Ciencias Sociales (IdIHCS). CONICET. Universidad \\ Nacional de La Plata, Argentina \\ (iD) Mauricio Schuttenberg \\ mauricioschuttenberg@gmail.com \\ Instituto de Investigaciones en Humanidades y \\ Ciencias Sociales (IdIHCS). CONICET. Universidad \\ Nacional de La Plata, Argentina
}

REVCOM. Revista científica de la red de carreras de Comunicación Social

Universidad Nacional de La Plata, Argentina

ISSN: 2451-7836

Periodicidad: Bianual

núm. 13, e069, 2021

redcom.revcom@gmail.com

Recepción: 23 Agosto 2021

Aprobación: 01 Diciembre 2021

URL: http://portal.amelica.org/ameli/journal/203/2032750012/ DOI: https://doi.org/10.24215/24517836e069

\section{c) (i) (2)}

Esta obra está bajo una Licencia Creative Commons AtribuciónNoComercial-CompartirIgual 4.0 Internacional.
Resumen: Este artículo propone ordenar el campo político argentino en torno a dos clivajes. El primero está representado por el clásico izquierda y derecha, el segundo por el peronismo y la posición antiperonista o "gorila". Luego de una caracterización de los espacios ideológicos, usamos conceptos de la física (masa, fuerza y campo gravitacional) para analizar la dinámica de los partidos políticos hacia las elecciones presidenciales de 2019. El estudio de la dinámica tanto al interior de cada espacio como en la totalidad del campo político permite apreciar la frágil estabilidad alcanzada. Este ordenamiento es condición de posibilidad y efecto de las estrategias políticas y los resultados electorales.

Palabras clave: política, Argentina, partidos políticos, izquierda, derecha, peronismo.

Resumo: Este artigo se propõe a ordenar o campo político argentino em torno de duas clivagens. $O$ primeiro é representado pelas clássicas esquerda e direita, o segundo pelo peronismo e a posição anti-peronista;. Após uma caracterização dos espaços ideológicos, utilizamos conceitos da física (massa, força e campo gravitacional) para analisar a dinâmica dos partidos políticos em relação às eleições presidenciais de 2019. O estudo da dinâmica tanto dentro de cada espaço como no conjunto político campo permite- nos apreciar a frágil estabilidade alcançada. Essa ordenação é condição de possibilidade e efeito das estratégias políticas e dos resultados eleitorais.

Palavras-chave: política argentina, partidos políticos, esquerda, direita, peronismo.

Abstract: This article proposes to organize the Argentine political field around two cleavages. The first is represented by the classic left and right, the second by Peronism and the "gorilla" (anti-Peronist) position. After a characterization of the ideological spaces, we use basic concepts of physics (mass, force and gravitational field) to analyze the dynamics of the political parties towards the 2019 presidential elections. The study of the dynamics both within each space and in the entire political field allows us to appreciate the fragile stability achieved. This order 
is a condition of possibility and effect of political strategies and electoral results.

Keywords: Argentina, political parties, left, right, peronismo.

\section{INTRODUCCIÓN}

El triunfo de una fuerza de centro-derecha en las elecciones de noviembre de 2015 en Argentina abonó la tesis de un "fin de ciclo" de los gobiernos del left turn o pink tilde que parecía confirmarse con el ascenso de Jair Bolsonaro en Brasil, la diestra radicalización en Colombia y la consolidación de gobiernos de este signo en Ecuador y Chile. La idea de un contra-ciclo y una nueva fase gobiernos de derecha inundó la literatura académica sobre la política en América Latina (Alemán, 2016; Vommaro, 2017; García Delgado y Gradin, 2017; Torrico, 2017; Natanson, 2018). A esto se le sumó, luego, la derrota del Frente Amplio en Uruguay y el golpe de Estado a Evo Morales en Bolivia como datos que confirmarían la tendencia.

El triunfo de Mauricio Macri y su asunción como presidente en 2015 fue efecto de (y tuvo efectos en) las transformaciones del campo socio-político en Argentina. Para este caso, la novedad fue la consolidación de una coalición de centro-derecha con capacidad electoral, con un nuevo estilo político y estrategias consistentes con nuevas formas de representación política que contemplan distintas lógicas de comunicación. Sin embargo, el triunfo de Alberto Fernández y Cristina Fernández de Kirchner en 2019 obligó a revisitar las preguntas sobre la conformación de este campo político en el que lo nuevo y lo viejo se articulan para dar lugar a determinadas configuraciones resultantes de la dinámica en los últimos años. La persistencia del peronismo como un "movimiento partidario" en el campo político ayuda a comprender la estrategia ganadora de las elecciones de 2019 y una serie de tensiones en un campo político que parece encontrar una nueva estabilidad contingente que encuentra en un polo de centro-derecha una presencia estructuraste.

En un trabajo anterior (Retamozo y Schuttenberg, 2016a) analizamos la dinámica del campo político argentino hacia las elecciones de 2015 y como corolario nos interrogábamos por los efectos que tendría el triunfo de CAMBIEMOS dado el peso de un polo en cierto modo novedoso por su constitución, marco de alianzas, estilo y desempeño electoral. Para ello, implementamos una propuesta heurística que puede resumirse en dos movimientos conceptuales. El primero enfatiza el replanteo de la particular estructura del campo político en Argentina y el segundo provee un esquema analítico para el comportamiento de los agentes que operan en este campo. El campo político en la Argentina lo consideramos estructurado en torno a dos ejes que configuran un plano. Al eje clásico entre izquierda y derecha le agregamos el de arriba y abajo que, como argumentamos, podemos resumir en peronismo y "gorilismo" ${ }^{1}$ (Retamozo y Schuttenberg, 2016b). Diversos autores, como Pierre Ostiguy (1999, 2005, 2013a, 2013b) y Alessandro (2009) han reparado en esta cuestión y la han identificado con "estilos" o "clivajes" que estructuran el campo político y son necesarios para comprender las fuerzas políticas en pugna y establecer sus dinámicas de interacción. Esto agrega una complejidad al campo político y nos conforma un plano con seis espacios porosos que ayudan a ubicar a las organizaciones políticas. Estas organizaciones se convierten en polos y forman campos de atracción de votantes en las coyunturas electorales. 


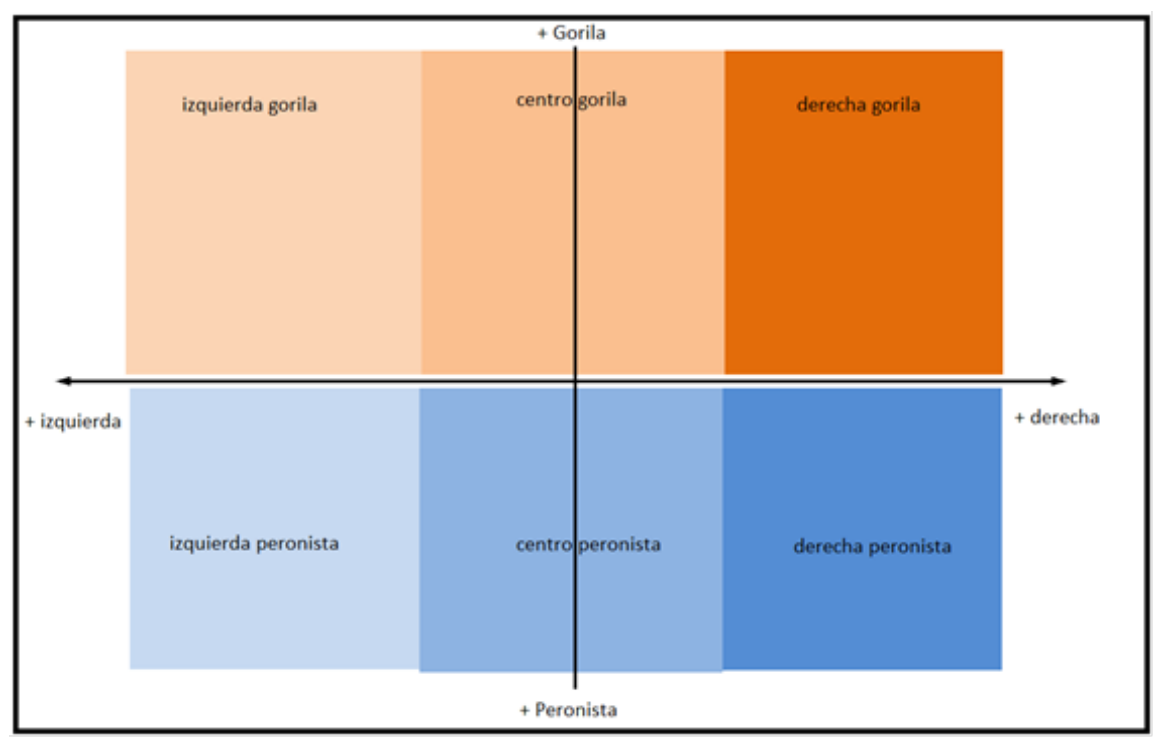

ESQUEMA 1

Retamozo y Schuttenberg (2016)

Para el análisis de las fuerzas políticas y sus relaciones hemos tomado la navaja de Ockham y operativamente, con fines heurísticos, algunos conceptos provenientes de la Teoría de la Gravitación Universa $^{2}$ de Isaac Newton, a saber: masa, fuerza y gravitación. En efecto, a los distintos grupos políticos (partidos o coaliciones) les asignamos determinada Masa $(M)$ que, por definición, es la cantidad de materia que tiene un objeto. Ese polo -electoral en nuestro estudio- construye un campo propio que produce un efecto de atracción (a votantes, partidos menores, dirigentes). Esta capacidad de lograr una Masa determinada define el nivel de atracción de un polo político (cuyo experimento crucial es el electoral). De este modo, cada grupo o polo generará un campo gravitacional propio que disputará con otros y tendrá efectos de acuerdo a esta Masa y la distancia en la que se ubique el objeto a atraer (dirigente, otro partido, votante). La Masa es, por definición, la cantidad de materia que tiene un objeto, en este caso los polos o frentes políticos (en tiempos electorales). Ahora bien ¿qué es lo que hace que determinado polo tenga cierta $M$ ? En nuestra investigación postulamos algunos indicadores: liderazgo, organización, recursos materiales, posiciones institucionales, situaciones mediáticas, expectativas de desempeño electorales e identidades (recursos simbólicos). La Masa de un polo se verifica en dos instancias. Por un lado, en el momento del armado de la oferta electoral (marco de alianzas e incorporación de dirigentes). Por otro lado, en el acto eleccionario que muestra los efectos sobre el campo político en cuanto a la atracción de votantes (allí tomamos como datos a los resultados electorales). El primer momento puede incrementar o disminuir la Masa para el segundo evento. Cabe aclarar que esta Masa -a diferencia del mundo físico- depende en buena medida del reconocimiento de una característica (ej. liderazgo, identificación, expectativa electoral), es decir, de una Masa imputada y que a la vez tiene efectos en el devenir de la objetividad histórica. ${ }^{3}$ Ahora bien, esta masa $M$ genera un Campo gravitatorio $(E->)$ en todo punto del espacio que apunta hacia el polo político. La magnitud $(E)$ de este campo puede enunciarse formalmente del siguiente modo

$$
E=\frac{G \times M}{d^{2}}
$$

donde $G$ es una constante y $d$ es la distancia del punto del espacio que estamos considerando a la masa. Esto quiere decir que, cuánto más $M$ tenga un objeto, mayor será el campo que genera, y que este campo se va haciendo cada vez más débil a medida que nos alejamos. El gráfico que expresa el campo que un objeto (polo político) genera puede expresarse de la siguiente manera: 


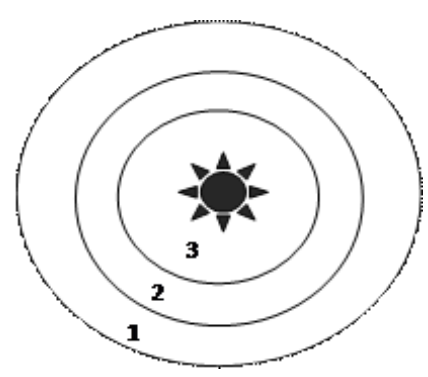

El campo $(E->)$ generado por la masa $M$ en el punto del espacio donde está ubicada $m_{0}$ ejerce sobre $m_{0}$ una fuerza $(F->)$ de atracción cuya magnitud $(F)$ es:

$$
F=E \times m_{0}
$$

Esto quiere decir que cuanto mayor es el campo generado por un objeto (cuanto más Masa tenga) mayor será la fuerza que ejercerá sobre una masa de prueba $m 0$ (el votante o el dirigente) y que cuanto más lejos esté el votante del objeto (el polo político), menor será la fuerza que este ejercerá. Los campos atraen, en el caso que analizamos, primero partidos y dirigentes y, luego, votantes. En este trabajo ajustamos esta perspectiva teórica para ofrecer un análisis de la dinámica del campo político bajo la presidencia de Mauricio Macri (2015-2019). En particular, nos enfocamos en los eventos electorales de 2017 y 2019 como coyunturas que permiten el análisis de la estructuración del campo político. En el caso de las elecciones de 2017, tomamos los resultados de la provincia de Buenos Aires por dos razones fundamentales. La primera es que en este distrito electoral se concentra casi el $40 \%$ del padrón y la segunda es que allí se dio una contienda clave ("la madre de todas las batallas") por el peso electoral mencionado y por los contendientes que eligieron ese distrito para presentar sus candidaturas. En efecto, en 2017 en la categoría a senadores nacionales compitieron el ex Ministro de Educación, Esteban Bullrich, por la fuerza oficialista, Sergio Massa (ex-candidato a presidente en 2015), Florencio Randazzo (ex-Ministro del Inerior y Transporte y pre-candidato a presidente en 2015) y Cristina Fernández de Kirchner (presidenta entre 2007 y 2015). La presencia directa de CFK otorgó una atención (y una tensión) particular en ese proceso electoral. En el caso de 2019 tomamos los resultados nacionales a presidente por obvias razones de relevancia. El artículo lo estructuramos del siguiente modo: a continuación, dedicaremos una sección a presentar los espacios políticos relevantes para el período y haremos una breve caracterización de su composición. Luego dedicaremos respectivas secciones a las elecciones de 2017 y 2019. Como corolario presentaremos el análisis de la dinámica y las perspectivas abiertas luego del triunfo electoral de la fórmula peronista en 2019.

\section{La política argentina: campos en pugna}

Como argumentamos, el espacio político argentino puede dividirse en seis cuadrantes. A continuación, expondremos la conformación de los cinco que contienen a las fuerzas políticas con representación electoral (ya que la derecha peronista carece de un polo de representación electoral propia).

\section{La izquierda argentina: alta/gorila/antiperonista}

En el cuadrante de la izquierda alta, gorila (no o anti peronista), encontramos diferentes polos que "suben" o "bajan" en función de su mayor o menor antiperonismo. ${ }^{4}$ Esto permite, potencialmente, distinguir una izquierda ubicada en un alto-antiperonismo y una izquierda no-peronista (más abajo en el cuadrante) que incluso puede asumirse como nacional-popular e ingresar en la órbita del peronismo. En la actualidad, ese 
espacio es dominado por dos constelaciones. El primero el de la izquierda clasista, habitado por cuatro partidos trotskistas: PTS, PO, MST y Nuevo MAS. Desde el 2011 el PO y el PTS conforman el "Frente de Izquierda" que se ha consolidado como la referencia central de la izquierda clasista. Esto, por supuesto, no quita la existencia de otras fracciones que se han derivado de aquella máxima de que todo partido trotskista es divisible. Para las elecciones de 2019, se incorporó el MST al FIT, excluyendo al Nuevo MAS. Por otro lado, un espacio cuya gravitación ha evidenciado una lenta "baja" al punto de integrar frentes electorales con el Partido Justicialista y reivindicar figuras peronistas como Eva Perón y Cristina Fernández de Kirchner. Allí encontramos buena parte de la izquierda estudiantil de origen autonomista y al Partido Comunista Argentino. Las organizaciones "autonomistas", como veremos, revisaron sus posiciones de no presentarse a elecciones como su valoración del peronismo (a través del kirchnerismo), lo que produjo un descenso en el cuadrante. En efecto, organizaciones que se consolidaron en el escenario político con posiciones "autonomistas" (neo-zapatistas) en los años noventa (como los MTD y el FPDS), fueron ingresando en la órbita del movimiento nacional y popular estructurado en torno al peronismo. Fracciones disidentes de este espacio se han sumado a las tácticas electorales de los partidos trotskistas. En las elecciones presidenciales de 2015, el FIT obtuvo $3.23 \%$ de los votos, mientras que las otras organizaciones no se presentaron a elecciones o no pasaron el piso de $1.5 \%$ en las primarias. El Partido Comunista participó del frente electoral presentado por el peronismo kirchnerista que llevó como candidato a Daniel Scioli.

\section{El centro alto/antiperonista}

La constitución de un espacio de "centro-izquierda" o "socialdemócrata" ha sido el norte de muchas experiencias políticas en la argentina y el peronismo -siempre- ha sido esa anomalía de fractura. Estos intentos oscilan entre la búsqueda de ocupar un lugar en las preferencias electorales y su pretensión más profunda de reconfigurar todo el campo diluyendo el clivaje peronismo-antiperonismo para reemplazarlo por espacios de centro-izquierda y centro-derecha competitivos. La representación de este espacio ha ido mutando en las distintas coyunturas: en 2007 se disputaron el espacio la fórmula promovida por la UCR (Roberto Lavagna y Gerardo Morales) con la encabezada por Elisa Carrió (ARI). Luego, en 2011, Hermes Binner encabezó el Frente Amplio Progresista (Partido Socialista, UCR) y Margarita Stolbitzer en 2015 por el Frente Progresistas. Es cierto, también, que una parte de la UCR busca ubicar el polo de este partido en el centro-progresismo, sin embargo, la Alianza con el PRO desde 2015 lo ubicó en el espacio de la coalición de centro-derecha. Con la UCR y la Coalición Cívica recostados hacia la derecha en la coalición de gobierno, el espacio de centro-izquierda alto quedó desanclado de inscripción territorial más allá de la provincia de Santa Fe (hasta 2019) y sólo contaba con figuras como Margarita Stolbitzer, cuyo desempeño electoral en las elecciones de 2015 (2,61\%) evidenció una marcada debilidad para encarar estrategias propias y acumular ..

\section{La izquierda peronista}

El devenir del kirchnerismo, luego de su asunción el 25 de mayo de 2003, reactivó un espacio que no lograba articularse significativamente desde el retorno a la democracia: la izquierda peronista (Casullo, 2007). Este espacio, desplazado de la centralidad en el movimiento peronista, especialmente en la década del noventa, retornó a la escena desde el kirchnerismo como discurso y como sujeto. ${ }^{5}$ En efecto, la recuperación de una inscripción generacional en los años 70 y experiencias de los años 80 y 90 que buscaron actualizar la tradición nacional-popular en clave de movimiento de liberación, dotaron al kirchnerismo de capacidad de interpelar a sectores peronistas que no habían sido protagonistas en términos electorales (Casullo, 2007). A su vez, la ubicación en la cúspide del sistema político permitió articular con otros sectores del peronismo a través de gestiones institucionales de coordinación (tanto en el parlamento como en relación a gobernadores e 
intendentes). El kirchnerismo logró consolidarse en ese espacio político y extender desde allí su hegemonía, a la vez de amalgamar y producir organizaciones que reivindican su condición de peronistas como La Cámpora, Peronismo Militante, Kolina y funciona de referencia para organizaciones estudiantiles, sindicales y culturales. Luego de obtener el 54,11\% de los votos en las elecciones presidenciales de 2011, y de ser derrotado por Sergio Massa en 2013, el candidato de este espacio, Daniel Scioli, perdió el balotaje de las elecciones presidenciales de 2015, después de obtener 37,08\% en la primera vuelta.

\section{Un peronismo de centro}

El peronismo de centro es un espacio elusivo y a la vez en constante reemergencia. En la fase de transición a la democracia fue, en cierto modo, la Renovación Peronista los que intentaron ubicar al partido justicialista en unas coordenadas ideológicas específicas y generar una forma partidaria al movimiento. La irrupción de Carlos Menem, sin embargo, colonizó gran parte de ese espacio y produjo primero una escisión hacia la izquierda (El grupo de los 8) y luego un proceso de desperonización de las organizaciones nacidas de esta crisis (El Frente Grande y la Central de Trabajadores Argentinos). En este siglo, el espacio de centro en el peronismo estuvo dominado por la figura de Eduardo Duhalde que acompañó la candidatura de Néstor Kirchner en 2003. Sin embargo, luego ambos espacios se enfrentaron en las elecciones de 2005. La consolidación del kirchnerismo dejó poco espacio a este sector de centro hasta que, en 2009, Francisco De Narváez a través de la Unión-PRO gana las elecciones legislativas en el principal distrito y vence en la contienda al propio Néstor Kirchner. La buena performance de una oposición que articulaba a figuras como Mauricio Macri, Felipe Solá y Eduardo Duhalde en 2009 no pudo ser repetida en las presidenciales de 2011. Hacia las elecciones legislativas del 2013, ese sector fue hegemonizado por la figura de Sergio Massa (Piana y Baeza, 2013) (ex jefe de gabinete de Cristina Fernández) que triunfó en las elecciones en la provincia de Buenos Aires y se convirtió en un polo con gravitación en el espacio de la centro-derecha peronista en alianza con otros gobernadores o exgobernadores peronistas como Juan Manuel de la Sota (Córdoba), Jorge Busti (Entre Ríos) y Juan Carlos Romero (Salta). Este espacio llevó a Sergio Massa como candidato en las elecciones de 2015, en las que obtuvo el tercer lugar con el 21,39\% de los votos. El centro-peronismo se debilitó cuando apareció otra fuerza hacia la derecha con suficiente Masa para atrapar votos.

\section{El espacio de derecha alta/gorila}

A este espacio es preciso dedicarle especial atención ya que se transformó en un polo estructurante todo el campo político luego del 2015 como no lo había sido antes. Desde 1983 el espacio de derecha anti-peronista se construyó en torno a experiencias partidarias con escasa posibilidad de acceso al poder en elecciones. El antecedente con mayor impacto electoral e identitario fue la Unión del Centro Democrático (Ucede), partido que llegó a obtener casi 2 millones de votos en las elecciones de 1989. No obstante, en otra de las paradojas de la historia, este partido de tradición liberal-conservador y fuertemente antiperonista fue absorbido por el Partido Justicialista durante los años noventa.

Heredando esa tradición liberal conservadora, el ex ministro de economía de Menem, Domingo Cavallo fundó en 1999 el partido Acción por la República. Luego de una fallida participación en los comicios de 2001 se plegó tras la candidatura de Menem en 2003. En ese mismo espacio ideológico, luego de abandonar la Unión Cívica Radical en 2002, Ricardo López Murphy fundó el partido Recrear para el Crecimiento (Recrear). En 2003 se presentó a las elecciones como candidato a Presidente de la Nación, obteniendo el tercer lugar con el 18\% de los votos. Recrear para el Crecimiento proponía una profundización de las políticas neoliberales interpretando que en esos años la Argentina se habría distanciado del liberalismo. Estas vertientes las podríamos situar en el cuadrante propuesto, arriba y a la derecha. 
En 2007 se comenzó a gestar un polo de la derecha alta -aunque a nivel subnacional- con el triunfo de Mauricio Macri en las elecciones para la Jefatura de Gobierno de la Ciudad de Buenos Aires. En ese contexto, el PRO articuló un discurso en abierta oposición al gobierno nacional y de alineamiento antagonista en cada uno de los conflictos, especialmente luego de la Resolución 125, que derivó en un conflicto con los empresarios del sector agrario, y la "Ley de Medios". 6 Allí, este partido se instaló con un discurso crítico de la intervención Estatal y de la primacía de la política por sobre la economía. El espacio del electorado de centro-derecha "huérfano" de representación política comenzaba a vislumbrar una oferta electoral, que en la provincia de Buenos Aires llevó como candidato al empresario Francisco de Narváez.

En 2011, Macri obtuvo la reelección en la Ciudad de Buenos Aires. Este desempeño electoral contribuyó a que el PRO se convirtiera en un locus de identificación polimorfe que incluía sectores inscriptos en la tradición liberal-conservadora, pero también otros sectores atraídos por un discurso modernizador y pospolítico. En esa estrategia podemos observar un abandono de la reposición recurrente de sentidos más típicamente gorilas por un enfoque deliberada e ideológicamente desideologizado. ${ }^{7}$ Un ejemplo sería el impulso que Vommaro y Morresi y Belloti (2014) y Schuttenberg (2017) señalan que, a diferencia de otros partidos de centro-derecha argentinos como la Ucedé, el PRO no se presenta como un partido doctrinario, con una ideología manifiesta o un proyecto de país claramente delineado y, a diferencia de los partidos tradicionales de derecha en Argentina, no surge como organización de énfasis antiperonista y, por esa razón, pudo disfrutar de un electorado potencial más grande que sus antecesores.

A su vez, el desafío de un partido fortalecido a nivel local fue replicar el crecimiento y gravitación a nivel nacional que obtuvo en el distrito Capital Federal. Allí los desplazamientos operaron tanto en un nivel horizontal -acercando posiciones con la UCR hasta encontrarse debido al desplazamiento de ésta hacia la derecha- como vertical para gravitar en el espacio dominado por el peronismo de centro derecha. ${ }^{8} \mathrm{La}$ decisión orgánica de la UCR en la Convención de Gualeguaychú de participar de unas Primarias con el PRO y de la Coalición Cívica de Elisa Carrió en el mismo sentido, construyeron un frente electoral competitivo. Como corolario de este proceso, en las elecciones del 2015, la coalición de centro-derecha CAMBIEMOS (UCR, CC y PRO) logró llegar a la presidencia de la Nación al vencer al candidato del Partido Justicialista en el balotaje.

En las elecciones de 2015, el campo político puede graficarse del siguiente modo: 


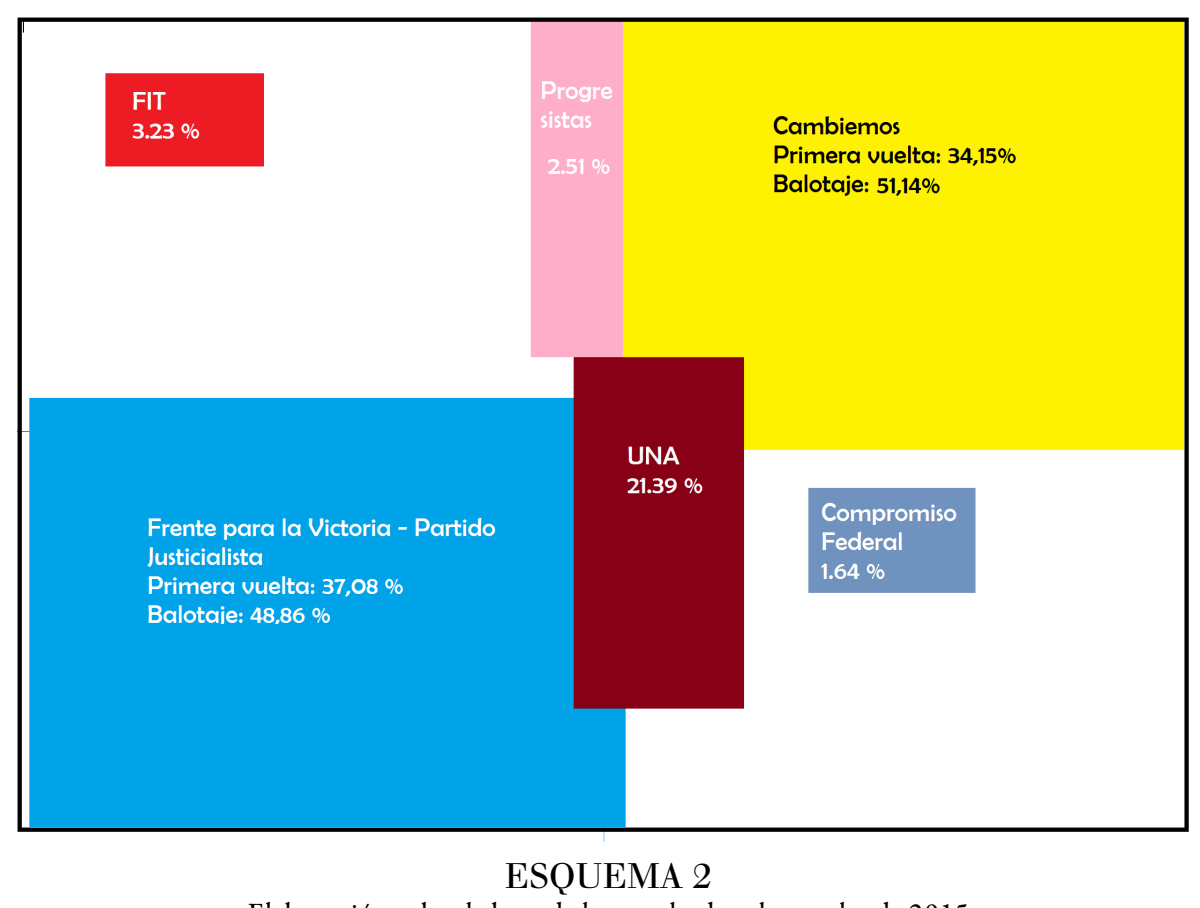

Elaboración sobre la base de los resultados electorales de 2015

\section{HACIA 2017: UNIDAD DEL OFICIALISMO Y FRAGMENTACIÓN DE LA OPOSICIÓN}

El resultado de las elecciones de 2015 dejó un campo político con varias novedades. En primer lugar, la coalición de centro-derecha CAMBIEMOS mostró su eficacia electoral y se consolidó como un polo de atracción para todo el electorado de derecha y buena parte del centro, tanto gorila como -especialmente, en el balotaje- del peronismo distanciado del kirchnerismo. En segundo lugar, la división del peronismo entre un peronismo kirchnerista (hacia la centro-izquierda) y el Frente Renovador de centro-derecha se plasmó en la primera vuelta donde obtuvieron $37.08 \%$ y $21.39 \%$ respectivamente. Sin embargo, ese voto no pudo ser conservado en su totalidad por Daniel Scioli y una parte significativa emigró hacia Mauricio Macri, evidenciando su carácter de votos ubicados en el centro no-peronista. La victoria de una fuerza emergente que articulaba posiciones tradicionales en el espacio político argentino con estilos (de campaña, liderazgo y comunicación) nuevos fue, sin dudas, una novedad. Por otro lado, la derrota del peronismo (dividido) agudizó tensiones internas e intentos de reconfigurar las representaciones de ese espacio. La izquierda consolidó un número de votos estable pero poco significativo y el espacio de centro izquierda antiperonista salió muy debilitado de la contienda electoral (terminó por debajo de la izquierda trotskista). En estas situaciones se encontraban los polos en el escenario previo a las elecciones legislativas de 2017.

\section{El polo de centro-derecha}

Hacia las elecciones de 2017 puede apreciarse la consolidación del polo de centro-derecha CAMBIEMOS. En las elecciones de medio término, Cambiemos apostó a una fórmula "pura" en el principal distrito electoral, a la buena imagen de la gobernadora María Eugenia Vidal y una estrategia global de confrontación con el kirchnerismo (que eligió enfrentarlo con su principal figura en el escenario electoral). Así obtuvo triunfos en Buenos Aires, ciudad de Buenos Aires, Córdoba, Corrientes, Chaco, Entre Ríos, Jujuy, La Rioja, Mendoza, Neuquén, Salta, Santa Cruz, Santa Fe. Cambiemos sacó cuatro puntos más que la lista de Unidad Ciudadana y revirtió así el triunfo de la ex mandataria, quien en agosto había ganado por 20.000 votos 
las PASO. ${ }^{10}$ El polo se consolidó, primero con apoyos de los sectores dominantes y el sistema de medios hegemónico, para luego retroalimentarse con los resultados electorales. El clivaje cambio/pasado volvió a mostrarse eficaz para ordenar el espacio público mediatizado y el gobierno obtuvo el voto de confianza propio de las primeras elecciones de medio término de un nuevo ciclo de gobierno (como ocurrió siempre en la Argentina con excepción de las elecciones de 2001).

\section{El espacio de centro}

En un intento por recuperar protagonismo, los dos polos ubicados en el centro, cuyo electorado fue atraído por el polo CAMBIEMOS en 2015, confluyeron en un frente electoral. En efecto, los polos de centro peronista y centro gorila establecieron una alianza entre Margarita Stolbizer y Sergio Massa que formaron la propuesta 1País. Ese movimiento buscó dotar de Masa la opción ubicada en la "avenida del medio" que Massa venía impulsando, al intentar darle el volumen del espacio gorila alto representado por Stolbitzer. Sin embargo, en 2017 se ubicaron terceros en la provincia de Buenos Aires, ${ }^{11}$ muy lejos de los votos obtenidos por Cristina Fernández de Kirchner y evidenciando una pérdida de votos con respecto al desempeño de ambos candidatos en las elecciones de 2015. Evidentemente, la Masa conseguida con la alianza no pudo ser la suficiente para atraer del campo gravitacional de la derecha-gorila (Cambiemos) y de la izquierda peronista (Unidad Ciudadana), cuyos campos se consolidaron como estabilizadores. El espacio de centro se debilitó en tanto estrategia de articulación entre posiciones peronistas y antiperonistas, se mostró poco eficaz para acumular. En efecto, Sergio Massa volvió a caer en cantidad de votos (de los 3.943.056 que había obtenido en 2013 a 1.069.747). La alianza entre el GEN y el Frente Renovador se disolvió rápidamente luego de 2017, en parte por los magros resultados electorales y en parte por las tensiones que tradiciones políticas disímiles evidenciaron en el armado político. El intento de darle una base peronista al centro no tuvo una gran repercusión electoral puesto que el voto del GEN se ubica alto en el cuadro y el de Massa medio-abajo. Luego de esta experiencia, el GEN volvió a su espacio alto centro-progresista al recomponer la anterior relación con el Partido Socialista (fuerza por entonces gobernante en la provincia de Santa Fe). En un encuentro celebrado en la Ciudad de Buenos Aires, el progresismo se perfiló con una estrategia autónoma hacia el escenario electoral para el año 2019. Por su parte, el Frente Renovador entró en una fase de declive por el alejamiento de figuras como Alberto Fernández, Daniel Arroyo, Felipe Solá y Facundo Moyano, que le quitaron M y fuerza a ese polo.

\section{Espacio de izquierda alta /gorila}

En el cuadrante de la izquierda-arriba, el FIT se consolidó con una Masa que lo constituyó en el único polo que superó las PASO en las elecciones de 2017 en los principales distritos. ${ }^{12}$ El desempeño del FIT en estas elecciones significó la votación más alta del Frente desde su creación en 2011. Asimismo, en la provincia de Buenos Aires la lista a diputados del Frente, encabezada por Nicolás Del Caño y Romina Del Plá, alcanzaba el cuarto puesto con el 5,34\% de los votos, superando a la liderada por Eduardo Bali Bucca (Frente Justicialista) a la que relegó al quinto puesto con el 5,20\%. ${ }^{13}$ Por otro lado, la izquierda (ex)autonomista participó en CABA de las PASO en el marco del espacio vertebrado por el peronismo porteño. ${ }^{14}$ En otros distritos llevaron candidatos propios, pero con un llamado a votar a CFK en la categoría senadores nacionales por la provincia de Buenos Aires. Esto marca un "descenso" de posiciones antiperonistas (no exento de tensiones y rupturas) producidos por la atracción de la figura del polo peronista kirchnerista. 


\section{Centro-izquierda peronista}

En el cuadrante de la izquierda peronista tuvo lugar una disputa entre dos polos. Por un lado, la expresidenta Cristina Fernández de Kirchner lanzó su postulación por "Unidad Ciudadana” que prescindió de la estructura partidaria en la provincia de Buenos Aires, pero sumó a la mayoría de los intendentes y los distritos locales del partido. Este polo acumuló Masa al contar con una candidatura competitiva (con un presumible piso de votos altos pero un techo relativamente bajo) y eso atrajo a los jefes comunales que preferían vincular sus candidaturas a la tracción de la figura de Cristina. Por otro lado, en el mismo espacio, la candidatura de Florencio Randazzo constituyó una apuesta al "poskirchnerismo" que atrajo a figuras del espacio de Frente Renovador (como Alberto Fernández) y de los movimientos sociales (como el Movimiento Evita). Las negociaciones entre ambas opciones estuvieron abiertas y, luego de desechar un acuerdo de unidad o una competencia en las PASO, el resultado fue la propuesta de una contienda en las elecciones generales. Los resultados electorales en la Provincia de Buenos Aires en la categoría de "senadores", fueron los siguientes:

$\begin{array}{lll}\text { Frente electoral } & \text { Votos } & \text { Porcentaje } \\ \text { CAMBIEMOS } & 3.912 .526 & 41,38 \\ \text { UNIDAD CIUDADANA } & 3.529 .900 & 37,25 \\ \text { 1PAIS } & 1.069 .747 & 11,32 \\ \text { FRENTE } & 500.945 & 5,31 \\ \text { JUSTICIALISTA } & & \\ \text { FRENTE DE } & 448.933 & 4,75 \\ \text { IZQUIERDA } & & \end{array}$

En nuestro plano, los mismos pueden distribuirse del siguiente modo:

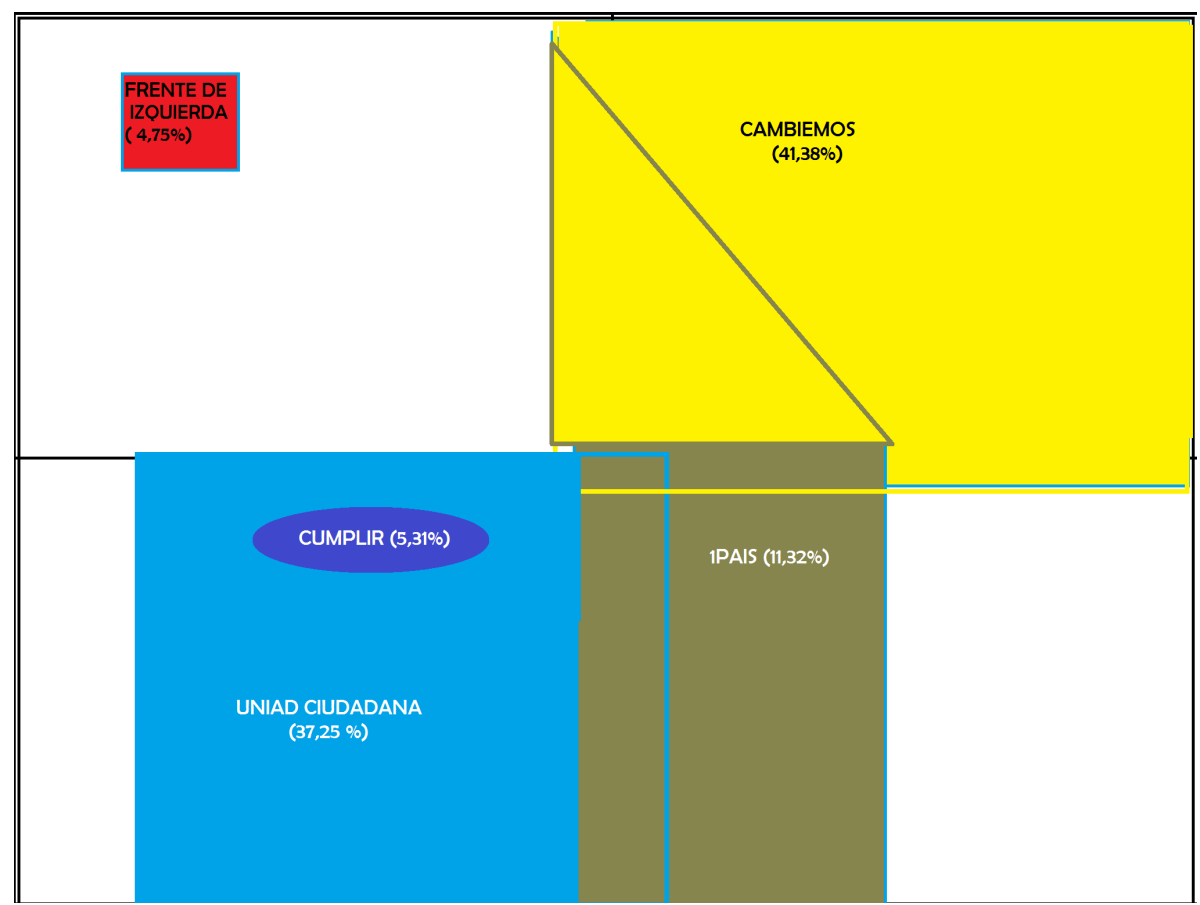

ESQUEMA 3

Elaboración propia sobre la base de los resultados electorales de 2017 para la categoría de Senadores de la Provincia de Buenos Aires. 


\section{HACIA 2019: DEBILIDAD OFICIALISTA Y UNIDAD OPOSITORA}

Las elecciones de 2017 arrojaron la consolidación del polo CAMBIEMOS, mientras que la oposición parecía replicar los mismos espacios de las elecciones de 2015, incluso incrementar la fragmentación. El liderazgo de Cristina Fernández continuó claro para el peronismo kirchnerista y otros sectores de izquierda nacional y popular que veían en la expresidenta una alternativa competitiva al gobierno de Mauricio Macri. Sin embargo, otros sectores del peronismo cuestionaban esta posibilidad. El resultado parecía una especie de paradoja. Por un lado, CFK mostraba tener un piso alto de votos fidelizados pero insuficientes para ganar en primera vuelta y con dudosas perspectivas en un posible balotaje. Por otro lado, las alternativas peronistas (que en 2017 fueron encabezadas por Randazzo y Massa) no lograban llegar cerca del piso de votos de la ex mandataria con lo que requerían una fuerte transferencia de votos para ser competitivos. Con un centro debilitado por la mala performance electoral del 2017 y una izquierda consolidada con el FIT como principal polo, se inició la carrera hacia las elecciones generales de 2019 en un contexto de deterioro de los principales indicadores socio-económicos.

\section{El espacio de derecha alta/gorila}

Desde 2015, la alianza Cambiemos articuló una propuesta que desde la derecha alta/gorila logró atraer cierto espacio del peronismo de derecha y captó así parte los fragmentos de la centro-derecha peronista y los escombros del FR en la segunda vuelta electoral. El discurso pos-ideológico del PRO tenía la flexibilidad de proponerse como superador de antinomias (izquierda/derecha, peronismo/antiperonismo) a la vez que activar estos clivajes en su forma "república/populismo" o "Futuro/Pasado). Es cierto que en el entramado político el PRO se dotó de cuadros provenientes del peronismo (como el Presidente de la Cámara de Diputados, Emlio Monzó), pero su ubicación en el espacio le permitía una especie de flotación de amplio espectro y discurso segmentado. En efecto, podía fluctuar desde posiciones de centro hasta de extrema derecha, subir hacia el antiperonismo clásico y bajar, morigerando su gorilismo. En este contexto, la coalición de centro-derecha-alta buscaría la triple reelección, es decir la del presidente Mauricio Macri, la de Vidal en provincia de Buenos Aires y la de Rodríguez Larreta en Ciudad Autónoma de Buenos Aires. Sin embargo, las fluctuaciones hacia abajo y hacia el centro como órbitas para atraer votos dejó "libre" un espacio en el que emergieron alternativas ubicadas a la derecha en el campo político. Por un lado, una corriente de opinión neoliberal radicalizada o libertaria con capacidad de instalación mediática en las figuras de Javier Milei y José Luis Espert. Este espacio apuntó a posicionarse a la derecha del oficialismo cuestionando su supuesto gradualismo en el tratamiento del déficit fiscal y la reforma del Estado "populista". Aunque con desacuerdos a la hora de ofrecer una alternativa electoral, finalmente José Luis Espert lanzó su candidatura presidencial para las elecciones de 2019 por el Partido Libertario haciendo eje en la necesidad de "dejar atrás ese pasado vergonzoso que ha significado el kirchnerismo" y derrotar "el presente mediocre que es el macrismo". "La verdadera alternativa a Cristina y a Macri somos nosotros” fue un lugar común de su discurso. ${ }^{15}$

Por otro lado, se configuró un espacio de la derecha baja, con tintes nacionalistas y conservadores que articuló un discurso anti-política con la promesa de vuelta a valores tradicionales, familiares y religiosos. A fines de 2018, el diputado Alfredo Olmedo lanzó su postulación y señaló: "En estos momentos, el país pasó de tener una política en donde solo le fue bien a los políticos, y quedaron quebradas la cultura del trabajo, las instituciones y las familias". Desde este sector se cuestionaba al gobierno de Cambiemos por su carácter liberal, por "habilitar" la discusión del aborto, por su "mano blanda" en cuestiones como "ideología de género, de querer aprobar el aborto, romper a la familia y dejar afuera a Dios del contenido de una Nación”. ${ }^{16}$ Finalmente fue Juan José Gómez Centurión, un exmilitar, el que encabezó una fórmula con eje en la lucha 
"por las dos vidas", en referencia a la defensa de posiciones contrarias a la efectivización del derecho al aborto. Por primera vez, dos polos se ubicaban "a la derecha" de CAMBIEMOS.

\section{El peronismo de centro}

En el 2015, Sergio Massa intentó avanzar hacia un lugar desierto de fuerzas gravitacionales: la derecha peronista, y matizó su discurso para lograr inserción en electorado moderadamente gorila desde una posición de centro-derecha peronista. Este movimiento vertical de Massa obedeció en parte a la apuesta fuerte del FPV de llevar como candidato a Daniel Scioli ubicado hacia el centro peronismo, quedando poco espacio allí para construir una opción. Como mostramos en el apartado del progresismo, el frente Renovador se articuló con el GEN de Margarita Stolbizer para 2017. Ese frente se disgregó rápidamente y el Frente Renovador intentó aglutinar la etapa de renovación del peronismo al intentar atraer a sectores peronistas no kirchneristas. Incluso con una baja performance electoral en 2015, Sergio Massa apostó a encabezar la oposición moderada al gobierno de Macri (al punto que éste lo presentó como el líder del peronismo en el Foro de Davos de 2016). Sin embargo, luego de un revés electoral significativo, en $2018^{17}$ el discurso de Massa se fue alejando de su oposición "racional o responsable", como se la definía, y endureció sus objeciones a la marcha del gobierno. En ese contexto, hubo un acercamiento espacial con otros sectores del peronismo e incluso del kirchnerismo. En octubre de 2018, los diputados nacionales Felipe Solá y Facundo Moyano anunciaron su alejamiento del bloque del Frente Renovador junto a otros tres legisladores del massismo. Acompañando a Solá y Moyano, los diputados Daniel Arroyo, Fernando Asencio y Jorge Taboada también se fueron de la bancada que se referencia en el ex diputado Sergio Massa, para formar un interbloque junto al Movimiento Evita y la diputada Victoria Donda ${ }^{18}$. El discurso de este sector se vertebró sobre la necesidad de la unificación del peronismo para ser una alternativa competitiva frente al macrismo.

No obstante, a comienzos de 2019, Massa junto a otros dirigentes del peronismo de centro-derecha como Miguel Ángel Pichetto (jefe del bloque de senadores del PJ), Juan Manuel Urtubey (gobernador de Salta), Juan Schiaretti (gobernador de Córdoba), con el apoyo de otros gobernadores, lanzaron Alternativa Federal, un armado que intentaba hegemonizar al peronismo desde el centro, dejando de lado al kirchnerismo como opción de izquierda. En el acto de lanzamiento, el 2 de abril en Mar del Plata, Massa destacó que "tenemos que poner de pie a cada argentino que quiera construir un nuevo gobierno". Y agregó: "Tenemos que ir a abrazarlo, aunque estemos peleados, pensemos distinto o tengamos diferencias. Tenemos que construir una Moncloa argentina", insistió en ese llamado a achicar distancias hacia la construcción de "una nueva mayoría”. Inmediatamente después, el senador Miguel Pichetto planteó como eje central la unidad nacional, pero fue algo más claro para poner distancias con líneas del justicialismo que se referenciaban en la expresidenta Cristina Fernández. Así, dijo que en este proyecto se elabora una alternativa "que no tiene nada que ver con el pasado" y proyecta "un futuro de cambio para Argentina" ${ }^{19}$ Dejar atrás el pasado implicaba dejar de lado la experiencia kirchnerista. Algo similar ocurrió con el lanzamiento de la candidatura de Roberto Lavagna (ex ministro de Economía de Néstor Kirchner y candidato a las elecciones en 2007 en alianza con la UCR), en un intento de articular desde el centro posiciones peronistas y progresistas-no peronistas. El derrotero de ambos espacios se explica, en gran medida, por el movimiento de otro polo determinante del campo político argentino: la centro izquierda peronista.

\section{El peronismo: de la izquierda al centro y el Frente de Todos}

En el campo del peronismo parecía replicarse una división de la oferta electoral. El espacio político conducido por Cristina Fernández de Kirchner ya había mostrado su capacidad electoral en las elecciones de 2017, aunque la ex presidenta no había confirmado candidatura para las elecciones presidenciales. Además, en el 
principal distrito electoral -la provincia de Buenos Aires- emergía con proyección electoral la figura del ex ministro de Economía del kirchnerismo, Axel Kicillof. El cambio de estrategia política desde Unidad Ciudadana (con una centralidad discursiva en la forma de representación) hacia una construcción más tradicional de "frente popular" posibilitó el acercamiento de Cristina con referentes de organizaciones políticas, sindicales y distintos cuadros del "campo nacional y popular". La fuerza ejercida por la potencia electoral y esta apertura (que habilitó gravitaciones hacia el centro) permitió disputar la influencia del armado de Alternativa Federal, a la vez que no existían opciones que tuvieran influencia en el espacio de izquierdabaja del peronismo.

En ese contexto, sin una candidatura confirmada o avalada por CFK, se fueron lanzando distintos referentes del peronismo y del peronismo/kirchnerista como posibles representantes de ese espacio de izquierda baja del peronismo. De esta forma atisbaron las candidaturas de Agustín Rossi y Felipe Solá (con el apoyo del Movimiento Evita) a nivel nacional y el intendente de Lomas de Zamora, Martín Insaurralde, a la gobernación de la provincia de Buenos Aires.

El debate en el espacio de peronismo se vertebró en el problema de la "unidad" y la construcción de una alternativa al gobierno de Macri. La idea de que "con Cristina no alcanza y sin ella tampoco se puede" expresaba con claridad la tensión y la disyuntiva que atravesaba por esos momentos el espacio. De forma inesperada por el resto de las fuerzas políticas y con una amplia distancia temporal con el cierre de listas con vistas a las PASO, el sábado 18 de mayo de 2019 Cristina Fernández anunció, con un video que rápidamente se viralizó, la candidatura a vice presidenta en fórmula con Alberto Fernández como candidato a presidente. Fernández había sido jefe de Gabinete de todo el gobierno de Néstor Kirchner y una parte de la administración de CFK. Sin embargo, luego de su alejamiento fue jefe de campaña de Sergio Massa en las presidenciales de 2015 y de Florencio Randazzo en 2017. "Alberto" se encontraba trabajando en la articulación con figuras del peronismo (especialmente gobernadores y sindicatos) en aras de acumular M para que el espacio liderado por el kirchnerismo sumara competitividad electoral. Su vínculo con otros espacios del peronismo y un perfil más moderado le permitían amalgamar organizaciones y cuadros políticos que habían establecido distancias con el kirchnerismo.

Esta decisión dislocó todos los ejes de construcción política dentro del campo no oficialista y también los de la alianza Cambiemos. El poner un hombre cercano en otras épocas al kirchnerismo, pero que a su vez había sido muy crítico y que hasta hacía poco era cercano al Frente Renovador, modificó absolutamente el ordenamiento de las fuerzas:

Fue jefe de Gabinete de Néstor (Kirchner) durante toda su presidencia. Lo vi junto a él decidir, organizar, acordar y buscar siempre la mayor amplitud posible del gobierno. Fueron tiempos muy difíciles, pero éstos que estamos viviendo son realmente dramáticos. Nunca tantos y tantas durmiendo en la calle. ${ }^{20}$

Una primera muestra de gravitación se dio rápidamente con la baja de las candidaturas de Felipe Solá y de Agustín Rossi. Inmediatamente, la figura de Alberto Fernández comenzó a atraer a referentes del polo peronista no kirchnerista. Obviamente la figura de Cristina Fernández como vice presidenta otorgó el apoyo de la izquierda peronista. La jugada estratégica cerró múltiples tableros. Por un lado, tuvo un efecto inmediato en encapsular la fuerza que venía cobrando impulso y que disputaba el espacio de oposición que era Alternativa Federal. Esta fuerza fue perdiendo peso propio. En efecto, con un polo peronista más unificado y con potencia electoral, la opción por apostar a una dudosa construcción sin garantías hizo que gobernadores e intendentes prefirieron apostar al espacio promovido por CFK: el "Frente de Todos". En este escenario, el Frente Renovador acordó integrar al Frente de Todos y el líder de ese espacio Sergio Massa se postuló como primer candidato a diputado nacional en la provincia de Buenos Aires, con la promesa de encabezar la Cámara de Diputados si los resultados eran auspiciosos. La incorporación de Massa junto a otras agrupaciones políticas menores (como el Partido por la Cultura, la Educación y el Trabajo de Hugo Moyano, Proyecto Sur de Pino Solanas, Unidad Popular de Víctor De Gennaro y el Partido del Trabajo y del PuebloPartido Comunista Revolucionario, Patria Grande, entre otros) fue incrementando la Masa de una opción 
que en su tensión dividió el campo político. Por otro lado, quitó del centro de la escena mediática a la figura de Cristina, afectando la estrategia de CAMBIEMOS de antagonizar con la ex presidenta, a la vez que garantizó el caudal de votos "duros" del kirchnerismo.

\section{Opciones de centro}

La aparición de Roberto Lavagna, impulsada por una parte del peronismo de centro y con vínculos con sectores altos, de centro (y su negativa a participar en las PASO de Alternativa Federal), puso en tensión a este espacio. El espacio terminó por disolverse cuando Miguel Ángel Pichetto aceptó el ofrecimiento de la coalición gobernante para integrar la fórmula con la que Mauricio Macri buscaría su reelección. Este movimiento pretendió incluir un elemento peronista que atraiga votos de ese sector y marque una división entre un peronismo "responsable", "racional", "republicano", y un peronismo populista encarnado en la figura de CFK y por extensión a su espacio. Algo similar impulsó Roberto Lavagna al incluir a Juan Manuel Urtubey como candidato a vicepresidente.

Como señalamos, el primer impacto de esta estrategia política desplegada por Cristina Fernández fue la fragmentación de Alternativa Federal. Las principales figuras de ese espacio se fueron reubicando luego del anuncio de la candidatura de Alberto Fernández. Así, Massa y algunos gobernadores pasaron al Frente de Todos y Miguel Pichetto pasó a integrar la fórmula presidencial con Mauricio Macri formando Juntos por el Cambio. En tanto, Urtubey se vinculó a Roberto Lavagna y su propuesta Consenso Federal 2019, espacio en el que se presentó como candidato a vicepresidente.

\section{2019. PASO y POLARIZACIÓN EN PRIMERA VUELTA}

Con el escenario anteriormente trazado, se llevaron a cabo las Primarias Abiertas Simultáneas y Obligatorias en agosto. El resultado arrojó un importante triunfo del candidato a presidente del Frente de Todos, Alberto Fernández, con el 47,32 por ciento de los votos, y a una distancia de 15 puntos de ventaja del presidente Mauricio Macri (Juntos por el Cambio), quien obtuvo el 32,28\%, según los datos oficiales del escrutinio provisorio de la votación. Fernández y su compañera de fórmula, Cristina Fernández Kirchner, superaban así el 45 por ciento, la cifra que se necesitaría para ganar en primera vuelta en las elecciones generales de octubre. De la misma forma, en la provincia de Buenos Aires el candidato del Frente de Todos, Axel Kicillof, obtuvo un importante caudal de votos superando el 49\%, sacando una clara ventaja de casi 17 puntos por sobre los 32,57 de Eugenia Vidal. En tanto, en Ciudad de Buenos Aires, el candidato oficialista Horacio Rodríguez Larreta obtuvo también una importante diferencia con el candidato del Frente de Todos, lo que lo posicionó como favorito para las elecciones generales.

El escenario constituido en las PASO contribuyó a polarizar aún más los resultados en las elecciones generales de octubre de 2019 en las que las dos principales fuerzas concentraron casi el $90 \%$ de los sufragios. El funcionamiento de las Generales, con la información de las PASO operó - al menos en el caso de las opciones anti peronistas- como una situación de Balotaje. De hecho, las opciones ubicadas a la derecha de Juntos por el CAMBIO (NOS y Unite) obtuvieron menos votos en las elecciones generales que en las PASO.

Las elecciones de octubre consolidaron los resultados atisbados, con el sólo dato del recorte significativo de la diferencia que se había manifestado en las PASO entre las fórmulas del Frente de Todos y la de Juntos por el CAMBIO. 


\begin{tabular}{|c|c|c|}
\hline Frente electoral & Votos & Porcentaje \\
\hline $\begin{array}{l}\text { JUNTOS POR EL } \\
\text { CAMBIO }\end{array}$ & 10811586 & 40,28 \\
\hline FRENTE DE TODOS & 12946037 & 48,24 \\
\hline CONSENSO FEDERAL & 1649322 & 6,15 \\
\hline FRENTE NOS & 457956 & 1,71 \\
\hline FRENTE DE & 579228 & 2,83 \\
\hline $\begin{array}{l}\text { UNITE } \\
\text { UNA }\end{array}$ & 394207 & 1.47 \\
\hline
\end{tabular}

Resultados de las Generales 2019 (Fuente Ministerio del Interior https://www.argentina.gob.ar/interior/dine/elecciones2019)

El escenario constituido en las PASO contribuyó a polarizar aún más los resultados en las elecciones generales de octubre de 2019 en las que las dos principales fuerzas concentraron casi el $90 \%$ de los sufragios. El funcionamiento de las Generales, con la información de las PASO operó -al menos en el caso de las opciones anti peronistas- como una situación de Balotaje. De hecho, las opciones ubicadas a la derecha de Juntos por el CAMBIO (NOS y Unite) obtuvieron menos votos en las elecciones generales que en las PASO.

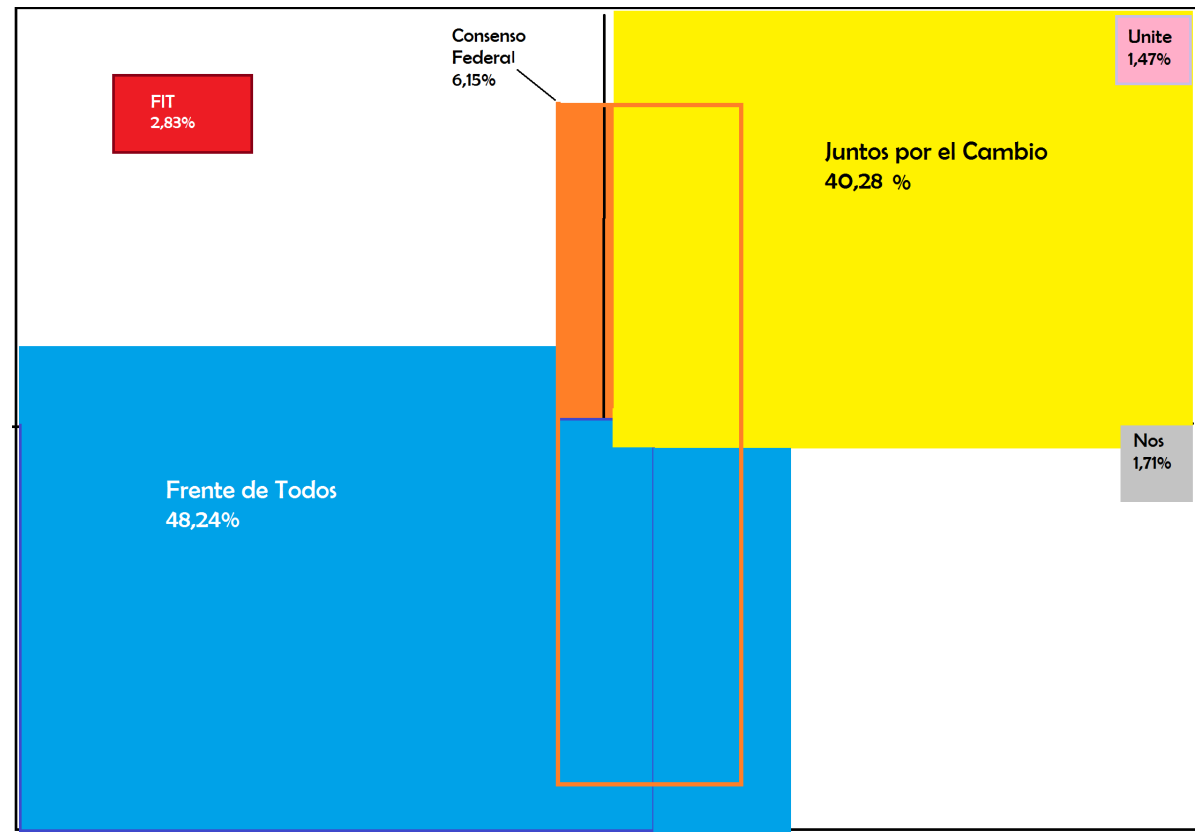

Elaboración propia en base a los resultados electorales a presidente de 2019

Los resultados electorales muestran como los dos polos principales construyeron y consolidaron Masa capaces de atraer organizaciones y votantes, mientras que las opciones que se ubicaron tanto a los extremos (derecha e izquierda) como en el centro, perdieron capacidad de fuerza. Cabe destacar que el polo promovido por Cristina Fernández de Kirchner mostró una capacidad para absorber la masa de las otras opciones peronistas, sus principales cuadros y votantes. La estrategia articulada por Cristina Fernández corrió el polo de gravitación del peronismo hacia el centro y de esa forma logró atraer a una serie de sectores que estaban más lejos del kirchnerismo "duro". Al no existir polos políticos ubicados en el cuadrante de izquierda abajo, no existió riesgo de fuga de referentes o votos (aunque la atracción, la fuerza ejercida o interpelación hacia ellos sea de menor intensidad). La opción de un frente alternativo a la continuidad neoliberal mostró su potencial electoral. 


\section{Conclusiones}

El resultado de las elecciones de 2015 consolidó un nuevo polo con Masa suficiente para ser gravitante en la producción de todo el campo político argentino. Ubicado en la centro-derecha-alta, CAMBIEMOS logró estabilizar una coalición gobernante y ofreció una representación política eficaz a preferencias electorales ubicadas en ese espacio. Asimismo, el dispositivo discursivo de Cambiemos (políticas, prácticas y discursos) tuvo eficacia en el nivel de las subjetividades sociales conformando un colectivo de identificación. El reenvío simbólico de la representación de las protestas contra el kirchnerismo y una estabilización en una matriz de sentidos que articula lo liberal con lo conservador mostró su productividad y explica la persistencia de este espacio. Por el otro lado, en el peronismo se disputaban formas de ejercer la oposición entre dos polos: el kirchnerismo desde una oposición frontal y el Frente Renovador desde una oposición de acompañamiento. Los gobernadores peronistas, por su parte, establecieron tácticas particulares de vínculo con el ejecutivo, mediado por la gestión de recursos. El espacio de izquierda autoidentificado como clasista, con escasa representación institucional, ejerció participación desde acciones de protesta.

Las elecciones legislativas de 2017 presentaron una fragmentación en el campo del peronismo en el principal distrito: la provincia de Buenos Aires. Allí, si bien el caudal de votos fue el habitual para el peronismo, la división en tres espacios liderados por el peronismo (Unidad Ciudadana, 1País y Cumplir) facilitó el triunfo de CAMBIEMOS con algo más del $40 \%$ de los votos. En retrospectiva, puede verse que, si bien derrotado, esta confrontación ayudó a ordenar el peronismo. Por un lado, mostró que el polo representado por la ex presidenta producía una $\mathrm{M}$ mayor que las otras opciones que disputaban el espacio. Por otro lado, ese mismo resultado dotaba de mayor materia a esta fuerza para posicionarse de cara a las presidenciales. Esto será clave en el proceso de unidad hacia esas elecciones de 2019.

En el otro cuadrante del campo político, el triunfo de la fórmula utilizada por CAMBIEMOS (que prescindió de integrar en lugares visibles a aliados) consolidó a este espacio como uno de los polos estructurantes del campo político, tanto en el juego electoral como en el de gestión.

A comienzos de 2019, se perfilaban tres espacios competitivos que buscaban acumular $M$ desde distintos lugares del espacio político. El primero era la Alianza Cambiemos desde la derecha-centro-alta (con la confirmada candidatura de Mauricio Macri a la reelección), el segundo el conducido por el kirchnerismo desde la izquierda peronista (con la latente candidatura de Cristina Fernández de Kirchner) y el tercer espacio surgía del centro del peronismo y algunos aliados del espacio de centro alto, en figuras como Sergio Massa y Roberto Lavagna.

En este marco, la alianza gobernante incentivaba su discurso anti kirchnerista como forma de polarización, mientras que las fuerzas alrededor del espacio liderado por Cristina Fernández buscaban ampliar su irradiación hacia otros espacios con algunos límites bastante marcados en ese objetivo. Un primer dilema para la fuerza gobernante lo propuso la aparición de los pequeños partidos ubicados a la derecha, tanto ultraliberales como ultra-conservadores, que no sólo amenazaban con quitarle votos, sino que desestabilizaban el discurso oficial. En efecto, la gravitación hacia el centro (en temas como el aborto o las políticas de asistencia social) comenzaron a tener costos posibles al perder fuerza (por la distancia) para atraer un voto de derecha. Este problema no había aparecido ni en 2015 ni en 2017 cuando no existió oferta electoral a la derecha de la Alianza Cambiemos, con lo que este polo conseguía atraer votantes de la derecha alta, aunque se desplazara tácticamente hacia el centro.

En un momento de definición de candidaturas y luego de rondas de negociaciones, la jugada de Cristina Fernández de proponer a Alberto Fernández como candidato a presidente y reservarse el lugar de vicepresidenta alteró todo el tablero político. La opción permitía mantener el voto kirchnerista fidelizado y "romper el techo" de una candidatura de CFK, tanto en cuanto a votantes potenciales como marco de alianzas. Esto sin dudas le otorgaba un significativo incremento de la Masa. Alberto Fernández, ex Jefe de Gabinete y ex Jefe de Campaña de candidatos como Sergio Massa y Florencio Randazzo, suministraba un 
capital político relevante decisivo en la conformación del "Frente de Todos" que se terminó de configurar con la inclusión de Sergio Massa y las principales figuras del Frente Renovador. Una vez conseguido un incremento de Masa, en el período pre-electoral, se sumaron otras agrupaciones políticas menores que de igual modo contribuyeron a la materia del Frente de Todos. La victoria de la Fórmula Fernández-Fernández con el 48,25\% y la obtención del 40,28 \% por parte de "Juntos por el Cambio" marca la estructuración polarizada del campo político, con un espacio pequeño en el centro y una marginalidad de la izquierda (expresada en 2 diputados sobre 257).

El fortalecimiento de la unidad peronista significó un refuerzo de expectativas para el polo de la Alianza gobernante "CAMBIEMOS", ahora nominada "Juntos por el Cambio". Como hemos argumentado, esta recepción de expectativas genera un incremento en la Masa del polo. La presencia de una coalición que puede moverse en el cuadrante de la centro-derecha-media y alta parece estabilizar el campo político argentino como contra peso de la centro-izquierda-media-baja representada por el peronismo. La Masa de ambos polos depende, en gran medida, de la consolidación de estos frentes y de la presentación espectral de la alteridad como "riesgo" (ya sea del "populismo" o del "neoliberalismo"). El camino hacia el 2021 en una gestión signada por los efectos ya perceptible y a la vez inciertos de la pandemia encuentra a los dos polos como indudables protagonistas de un campo que quizás, primera vez desde 1990, encuentre los mismos protagonistas competitivos en tres elecciones seguidas.

Es evidente que la pandemia mundial tendrá efectos económicos y políticos difíciles de vaticinar. Sin embargo, más allá de cómo esto afecte el resultado del proceso, parecen haberse consolidado ciertas coordenadas que marcarán el escenario político. En este horizonte, este análisis de la dinámica del campo político hacia las elecciones presidenciales de 2019 construye una plataforma para comprender como se constituyen campos y fuerzas para atisbar el devenir de la política en Argentina en el contexto reciente.

\section{Adenda 2021}

El artículo que presentamos lo terminamos de redactar en 2020, sin embargo el resultado de las elecciones legislativas de 2021 invita reflexionar a partir de los resultados de nuestras investigaciones previas. Más allá del efecto pandemia y de lo particular de las elecciones de medio término (que tradicionalmente fomentan dispersión), se confirma el escenario de polarización entre el peronismo y la centro-derecha en un tercer evento electoral $(2017,2019$ y 2021), con el crecimiento de opciones ubicadas a los extremos altos (el Frente de Izquierda compuesto por partidos trotskistas y las opciones de ultraderechas concentradas en Capital Federal y provincia de Buenos Aires). El dato más relevante, sin embargo, es que el peronismo perdió la superioridad que sus opciones sumadas habían logrado (con excepción del Balotaje de 2015). Como mostramos en otro trabajo y se refuerza en este, el caudal del peronismo (más allá de ir en diferentes opciones), siempre se ubicó en la provincia de Buenos Aires por sobre el $50 \%$ de los votos en las últimas dos décadas. Sin embargo, la derrota en provincia de Buenos Aires contra la coalición de centro derecha (39,81\% a 38,53\%) que se incrementa a nivel país $(41,89 \%$ a 33,03\%) abre un interrogante de cara a 2023. La cuestión de la conformación de preferencias del electorado en la pospandemia y la capacidad de potenciar la $\mathrm{M}$ de los polos en disputa (militancia, discursos, liderazgos) serán cuestiones claves para el escenario que se avecina. Asimismo, cabe reparar en la conformación de los polos, sus efectos de segmentación y la frontera antagónica que, además de la dimensión estratégica, parece incentivar la consolidación de sus núcleos constituyentes y la eficaz atracción hacia opciones de izquierda por parte del peronismo y del peronismo de derecha por parte de CAMBIEMOS/Juntos por el Cambio. Los espacios extremos lograron posicionarse en tanto a la ya consolidada opción de la izquierda trotskista se le suma una más lábil ultraderecha representada por Javier Milei y José Luis Espert. 


\section{REFERENCIAS}

Alemán, J. (2016). Horizontes neoliberales de la subjetividad. Ciudad Autónoma de Buenos Aires, Argentina: Grama.

Alessandro, M. (2009). Clivajes sociales, estrategias de los actores y sistema de partidos: la competencia política en la Ciudad de Buenos Aires (1995-2005). Revista SAAP, 3(3). Recuperado de https://revista.saap.org.ar/contenid o/revista-saap-v3-n3/Alessandro.pdf

Casullo, N. (2007). Las cuestiones. Ciudad Autónoma de Buenos Aires, Argentina: Fondo de Cultura Económica.

Fernández Constantinides, M. (2016). En su lugar y en su nombre. Disputas por la representación en el espacio público mediatizado (Tesis de doctorado). Facultad de Humanidades y Ciencias de la Educación, Universidad Nacional de La Plata. Recuperado de http://www.memoria.fahce.unlp.edu.ar/tesis/te.1359/te.1359.pdf

García Delgado, D. y Gradin, A. (2017). Neoliberalismo tardio: Entre la hegemonía y la inviabilidad. El cambio de ciclo en la Argentina. Ciudad Autónoma de Buenos Aires, Argentina: Facultad Latinoamericana de Ciencias Sociales (FLACSO).

Garategaray, M. (2010). Peronistas en transición. El proyecto político ideológico en la revista Unidos (1983-1991). Nuevo Mundo. Mundos nuevos [en línea], (10). https://doi.org/10.4000/nuevomundo.60126

Garategaray, M. (2013). Entre Perón y Alfonsín: notas sobre la Renovación peronista (1983-1988). Temas y Debates, (25), 35-57. https://doi.org/10.35305/tyd.v0i25.241

Hora, R. (2010). La crisis del campo del otoño de 2008. Desarrollo Económico, 50(197), 81-111.

Kitzberger, P. (2011). "La madre de todas las batallas": el kirchnerismo y los medios de comunicación. En A. Malamud y M. De Luca (Coords.), La politica en los tiempos de Kirchner (pp. 179-192). Ciudad Autónoma de Buenos Aires, Argentina: Eudeba.

Nardacchione, G. y Taraborelli, D. (2010). La importancia de los aliados: un estudio sobre el conflicto rural (marzojulio 2008). En R. Aronskind y G. Vommaro (Comps.), Campos de batalla. Las rutas, los medios y las plazas en el nuevo conflicto agrario. Ciudad Autónoma de Buenos Aires, Argentina: Prometeo.

Natanson, J. (2018). ¿Por qué? La rápida agonía de la Argentina kirchnerista y la brutal eficacia de la nueva derecha. Ciudad Autónoma de Buenos Aires, Argentina: Siglo XXI.

Ostiguy, P. (1999). Peronism and Anti-Peronism: Class-Cultural Cleavages and Political Identity in Argentina (Tesis de doctorado). Berkeley, United States: University of California.

Ostiguy, P. (2005). Les gauches en Amérique Latine: un état des lieux. Revue Internationale de Politique Comparée, $12(3)$.

Ostiguy, P. (junio 2013a). Politics, Populism, and Drama: On the Fusion of the Leader and the People. Ponencia presentada en la reunión de la Latin American Studies Association (LASA), Washington, D.C.

Ostiguy, P. (junio 2013b). Flaunting the 'Low' in Politics: A Cultural-Relational Approach to Populism. Ponencia presentada en el Workshop on the Concept of Populism, Universidad de Sussex.

Retamozo, M. y Schuttenberg, M. (2016a). La política, los partidos y las elecciones en Argentina 2015: ¿hacia un cambio en el campo político? Análisis Politico, 29(86), 113-140. http://dx.doi.org/10.15446/anpol.v29n86.58 046

Retamozo, M y Schuttenberg, M. (2016b). Gorila. Usos y controversias sobre la palabra en la Argentina contemporánea. Oficios Terrestres, (35), e002. Recuperado de https://perio.unlp.edu.ar/ojs/index.php/oficiost errestres/article/view/3701

Rofman, A. (2010). El modelo agrario rentístico financiero, sus características. En R. Aronskind y G. Vommaro (Comps.), Campos de batalla. Las rutas, los medios y las plazas en el nuevo conflicto agrario. Ciudad Autónoma de Buenos Aires, Argentina: Prometeo.

Schuttenberg, M. (2014a). Las identidades "nacional populares". De la resistencia noventista a los años kirchneristas. Córdoba, Argentina: Editorial de la Universidad de Villa María. 
Schuttenberg, M. (2014b). La oposición al kirchnerismo. Una aproximación a los posicionamientos y reconfiguraciones de la centro derecha (2003-2011). Sudamérica. Revista de Ciencias Sociales, (3), 51-74. Recuperado de http://fh.mdp.edu.ar/revistas/index.php/sudamerica/article/view/1051

Schuttenberg, M. (2017). La política de la despolitización. Un análisis de la construcción del relato PRO. Desafíos, 29(2). https://doi.org/10.12804/revistas.urosario.edu.co/desafios/a.5259

Taagepera, R. (2008). Making Social Sciences More Scientific: The Need for Predictive Models. Oxford University Press.

Torrico, M. (Ed.). (2017). ¿Fin del giro a la izquierda en América Latina? Gobiernos y politicas públicas. Ciudad de México, México: Facultad Latinoamericana de Ciencias Sociales (FLACSO).

Piana, R. y Baeza, N. (2013). Candidatos a medida ¿Cómo se construyó el candidato que le ganó a los Kirchner? En Revista Facultad de Derecho y Ciencias Politicas, 43(119), 773-800. Recuperado de https://revistas.upb.edu.co/ index.php/derecho/article/view/3310

Yabcobsky, N. (2010). Nosotros, ellos... Todos. Los sentidos de la representación política y los recursos discursivos utilizados para ganar legitimidad en el conflicto. En R. Aronskind y G. Vommaro (Comps.), Campos de batalla. Las rutas, los medios y las plazas en el nuevo conflicto agrario. Ciudad Autónoma de Buenos Aires, Argentina: Prometeo.

Vommaro, G., Morresi, S. y Belloti, A. (2014). Mundo PRO. Ciudad Autónoma de Buenos Aires, Argentina: Planeta.

Vommaro, G. (2017). La larga marcha de Cambiemos: la construcción silenciosa de un proyecto de poder. Ciudad Autónoma de Buenos Aires, Argentina: Siglo XXI.

\section{Notas}

1 En ese trabajo abordamos la compleja permanencia de la palabra "gorila" en el -como diría Borges- idioma de los argentinos. En efecto, si bien la preferimos por su potencia denotadora, puede ser reemplazada por los distintos grados de "no-peronismo"

$2 \mathrm{Al}$ respecto del uso de la física en las Ciencias Sociales, puede consultarse Taagepera (2008). Agradecemos a Mariano Salvay, Doctor en Física de la UNLP, por sus valiosos y didácticos aportes a la utilización de los conceptos provenientes de la Ley de la Gravitación Universal.

3 Un evaluador anónimo de este artículo observó, acertadamente, que es necesario contemplar también el efecto repulsión que repele a dirigentes, partidos o votantes y los inscribe en campos gravitatorios de las otras . del escenario político.

4 Una genealogía de las fuerzas políticas desde el retorno a la democracia puede consultarse en Retamozo y Schuttenberg, 2016 a.

5 Es cierto que luego de ser objeto de la represión de la dictadura cívico-militar, había intentado configurar una referencia. Muchos sectores de la militancia se volcaron en los años 80 en lo que se denominó la Corriente Intransigencia y Movilización, en el Peronismo Revolucionario y otras experiencias de corta duración (Ferrari, 2008). Una buena parte de la dimensión izquierda del peronismo se plasmó en la renovación peronista y en espacios como la revista Unidos (Garategaray, 2010 y 2013). Como reconstruye Schuttenberg (2014a), a partir de los testimonios de los militantes, los sobrevivientes de la generación del peronismo revolucionario hicieron varios intentos de reagrupar ese espacio político. En la década del noventa, estas experiencias cristalizaron en organizaciones como Peronismo Que Resiste, el Frente de la Resistencia y luego el Movimiento de Trabajadores Desocupados Evita, el MTD Resistir y Vencer, las 4 P (Pan y Poder para el Pueblo), MPRQ (Movimiento Patriótico Revolucionario Quebracho), el MP 20 (Movimiento Patriótico 20 de diciembre) y otras expresiones. Hasta la llegada de Néstor Kirchner mantuvieron escasa influencia, pero fueron interpelados por el discurso nacional y popular al punto de ser constitutivos del kirchnerismo como sujeto político.

6 Sobre los conflictos mencionados, puede verse: Fernández, 2016; Yabcobsky, 2010; Rofman, 2010; Nardacchione y Taraborelli, 2010; Kitzberger, 2011; Hora, 2010.

7 Esto no implica la presencia de enunciadores “típicamente” gorilas en el espacio. Esta presencia, así como de actores que reivindican formas de peronismo, hablan de la heterogeneidad y a la vez la segmentación del discurso de la coalición de centro-derecha.

8 Como muestra Alessandro (2009), el voto a Mauricio Macri provenía (en 2005) ya de votantes de Carlos Menem (derecha peronista) y Ricardo López Murphy (derecha gorila).

9 Nos referimos a la nominación de dos referentes del PRO como candidatos a senadores nacionales por la provincia de Buenos Aires. 
10 La Nación, 23 de octubre de 2017, “Elecciones 2017: en qué provincias ganó Cambiemos y dónde dio el batacazo", capturado en octubre de 2019: https://www.lanacion.com.ar/2074707-elecciones-2017-en-que-provincias-gano-camb iemos-y-donde-dio-el-batacazo

11 Perfil, 15 de agosto de 2017, Margarita Stolbizer admitió que la grieta "llevó a votar por miedo o enfrentamiento, capturado en octubre de 2019”: https://www.perfil.com/noticias/elecciones2017/stolbizer-reconocio-que-la-grieta-lle vo-a-votar-por-miedo-o-enfrentamiento.phtml

12 El MAS formó su propio frente en 2016 cuando se unió al Movimiento Socialista de los Trabajadores (MST) y crearon la Izquierda al Frente por el Socialismo, pero los resultados electorales no fueron los esperados. Consiguieron 61.716 votos para diputados nacionales y 8.420 para el Senado.

13 Telam, 14 de agosto de 2017, "El FIT obtuvo un 30\% más de votos que en 2015 y sus dirigentes creen que aumentarán su caudal en octubre”, capturado en octubre de 2019: http://www.telam.com.ar/notas/201708/198040-fit-izquierdaelecciones-2017-paso-marcelo-ramal-nicolas-del-cano-myriam-bregman.htm

14 El espacio que llevó como candidato a Itai Hagman terminó tercero detrás de las listas encabezadas por Daniel Filmus y Guillermo Moreno.

15 Clarín, 23 de diciembre de 2018, "José Luis Espert presentó el Partido Libertario y lanzó su candidatura presidencial”, capturado en octubre de 2019: https://www.clarin.com/politica/jose-luis-espert-presento-partido-libertario-lanzo-can didatura-presidencial_0_l-EmRpfFK.html

16 Informate Salta, 1 de noviembre de 2018, “Confiado en la gente, Olmedo lanza su candidatura a presidente”, capturado en octubre de 2019: http://informatesalta.com.ar/noticia/173037/confiado-en-la-gente-olmedo-lanza-su-candidatura -a-presidente

17 El destape web, 20 de enero de 2018, capturado en octubre de 2019: https://www.eldestapeweb.com/tras-las-idas-y-vu eltas-massa-y-stolbizer-el-frente-renovador-abandona-la-marca-1 pais-n38573

18 Perfil, 22 de octubre de 2018, "Felipe Solá y Facundo Moyano abandonan el Frente Renovador", capturado en octubre de 2019: https://www.perfil.com/noticias/politica/felipe-sola-facundo-moyano-abandonan-frente-renovador-de-serg io-massa.html

Ámbito, 21 de octubre de 2018, “Solá abandonó el Frente Renovador”, capturado en octubre de 2019: https://www.a mbito.com/sola-abandono-el-frente-renovador-y-lanzo-nuevo-bloque-otros-diputados-n 4037166

19 La Nación,4 de febrero de 2019, "En Mar del Plata Alternativa Federal lanzó su campaña”, capturado en octubre de 2019: https://www.lanacion.com.ar/2217315-en-mar-del-plata-alternativa-federal-realizo

20 Telam, 18 de mayo de 2019, "Cristina Kirchner anunció que será candidata a vice de una fórmula con Alberto Fernández”, capturado en octubre de 2019: https:/www.telam.com.ar/notas/201905/359235-alberto-fernandez-pre sidente-cristina-vice-cfk-formula-kirchnerismo-elecciones.html

21 Fuente diario Clarín del 11/08/2019 